\title{
Resultados preliminares do estudo da união de chapas de aços dissimilares pela técnica brasagem MIG
}

\author{
ABBADE, L. ${ }^{1 *}$; LARA, J. A. C. ${ }^{1}$; ROSSI, A ${ }^{1}$; ALENCAR, M. A. ${ }^{1}$, ROSSI, J. L. ${ }^{1}$; MUCSI, \\ C. S. ${ }^{1}$ \\ 1 Programa de Pós-Graduação em Tecnologia Nuclear, Instituto de Pesquisas Energéticas e Nucleares - IPEN. \\ *e-mail: Larissa-abbade@hotmail.com
}

\begin{abstract}
Resumo
A busca em fabricar veículos cada vez mais sustentáveis e seguros, por conta da crise dos recursos naturais e a preocupação com a segurança veicular, fez crescer o uso de novos matérias e métodos de conformação e união dos componentes da carroceria. As propriedades da coluna B determinam a segurança dos passageiros em caso de colisão lateral. A coluna B é constituída por materiais diferentes, e por isso, necessitam de um processo de união adequado. Assim, o objetivo do presente trabalho é realizar a caracterização mecânica da união entre o aço 22MnB5 tratado termicamente (têmpera) e o aço CR4, pela técnica brasagem MIG com adição do arame Cu-Si e o gás de proteção argônio. Os materiais utilizados foram, amostras do aço 22MnB5 revestidas por Al-Si e CR4 revestido por Zinco. A união foi realizada a partir de um projeto de corpo de prova, nomeado de furo oblongo regular. Os ensaios realizados (dureza Vickers e metalografia), se enquadram na norma AWS A5 C3. 3-2008. Os resultados obtidos, demonstraram uma queda na resistência mecânica na zona termicamente afetada pelo calor do aço 22MnB5, isso pode ter ocorrido devido ao aquecimento da região, que apresentou mudanças na microestrutura, porém a dureza desse material ainda é maior que no CR4. Nesse caso é foi possível concluir que mesmo com queda na resistência do aço 22MnB5, em um possível ensaio de tração o destacamento da união ocorreria no $\mathrm{CR} 4$, uma vez que a resistência deste material é menor.
\end{abstract}

Palavras-Chave: Brasagem MIG, CR4, 22MnB5, Al-Si.

\begin{abstract}
The search to manufacture increasingly sustainable and safe vehicles, due to the crisis of natural resources and the concern with vehicle safety, has increased the use of new materials and methods of forming and joining body components. The properties of column B determine the safety of passengers in the event of a side impact. Column B is made up of different materials and therefore requires an appropriate joining process. Thus, the objective of the present work is to carry out the mechanical characterization of the union between the heat-treated 22MnB5 steel (tempering) and the CR4 steel, using the MIG brazing technique with the addition of $\mathrm{Cu}$-Si wire and argon shielding gas. The materials used were samples of 22MnB5 steel coated with Al-Si and CR4 coated with Zinc. The union was made based on a specimen design, called a regular oblong hole. The tests performed (Vickers hardness and metallography), fall within the AWS A5 C3 standard. 3-2008. The results obtained showed a drop in mechanical resistance in the zone thermally affected by the heat of 22MnB5 steel, this may have occurred due to the heating of the region, which showed changes in the microstructure, however the hardness of this material is still greater than in CR4. In this case, it was possible to conclude that even with a drop in the resistance of 22MnB5 steel, in a possible tensile test, the detachment of the union would occur in the $\mathrm{CR} 4$, since the resistance of this material is lower.
\end{abstract}

Keywords: MIG Brazing, CR4, 22MnB5, Al-Si.

\section{Introdução}

As obrigações da Rota 2030, em relação à segurança veicular, é de que todos os veículos leves vendidos deverão adotar o mínimo de $65 \%$ de uma lista básica de sete dispositivos estruturais, que compreende: Proteção de impacto lateral, controle eletrônico de estabilidade, indicador de direção lateral, farol de 
rodagem diurna, aviso de não afivelamento do cinto do motorista, aviso de frenagem de emergência e visibilidade traseira [1].

Foi aprovada pela CCJ (Comissão de Constituição de Justiça) do senado brasileiro, é o Projeto de Lei $n^{\circ} 152$ de 2017, que tem como objetivo tornar obrigatório, que somente poderão ser vendidos os modelos de automóveis que tenham alcançado resultados mínimos em testes de impacto [2].

O impacto lateral, quando comparado com o frontal e o traseiro, é a segunda causa de morte no trânsito. Isso infelizmente acontece pois há pouco espaço e material para absorver energia dentro da cabine [3].

As carrocerias de materiais múltiplos são caracterizadas por um grande número de materiais dissimilares. Entre eles, destacam-se os aços ao boro, estampados a quente, utilizados em componentes estruturais e de segurança [4].

Ao longo dos anos, o processo de estampagem a quente, alcançou enorme sucesso na produção de peças com geometrias complexas e maior resistência mecânica ao material conformado. O aço estampado a quente (PHS) mais comercializado pela indústria automobilística é o 22MnB5 revestido por uma camada de Al-Si [5].

Para a união dos componentes fabricados a partir de chapas conformadas a quente, a soldagem é o processo mais utilizados, sendo que, cada veículo leva em média 3.000 pontos de solda [6].

Quando um automóvel possuí chapas de PHS e sofre um impacto lateral, caso os danos não sejam graves, é possível realizar um reparo. Porém a qualidade deste reparo, deve seguir as mesmas regras impostas no momento da fabricação [7].

O reparo em aços avançados de alta resistência (AHSS) é um assunto estudado pela indústria e pela literatura. Alguns autores, dizem que, a melhor forma de reparar uma solda, é seguir as recomendações do fabricante do veículo, se não existirem, utilizar o processo GMAW (Gas Metal Arc Welding), mais conhecido como soldagem MIG (Metal Inert Gas) [7].

A brasagem MIG consiste na união de aços, utilizando parte da técnica de aquecimento à arco elétrico, acrescentando um metal de adição, parecido com o processo de brasagem. Uma das características deste processo é a menor incidência de calor, em relação ao MIG convencional e o fato de que a união se faz por difusão do metal de adição e não pela fusão do material de base [8].

Desta forma, o presente trabalho apresenta a caracterização da união entre o aço estampado a quente (PHS) e o aço CR4, utilizando o processo de brasagem MIG, com a finalidade de avaliar 0 desempenho deste processo em relação a diferentes recomendações de reparo pela indústria automobilística.

\section{Metodologia}

Para a união por meio do processo de brasagem MIG foram utilizados dois tipos de material de base, sendo eles:

- Aço PHS: Foram recebidos para análise do processo MIG Brazing, amostras do aço 22MnB5, revestidas por $\mathrm{Al}-\mathrm{Si}$, tratadas termicamente (têmpera), com espessura de 1,40 mm, nas dimensões 75x150 mm.

- Aço CR4: Para análise do processo MIG Brazing, foram recebidas amostras do aço CR4, revestidas por $\mathrm{Zn}$, com espessura de $0,6 \mathrm{~mm}$. E foram cortadas em amostras nas dimensões 75×150 mm.

Os corpos de prova foram desenvolvidos e desenhados em conformidade com as recomendações da norma AWS C3.3:2008, com aplicativo CAD, utilizando um projeto, nomeado de furo oblongo regular, conforme figura 1 [9].

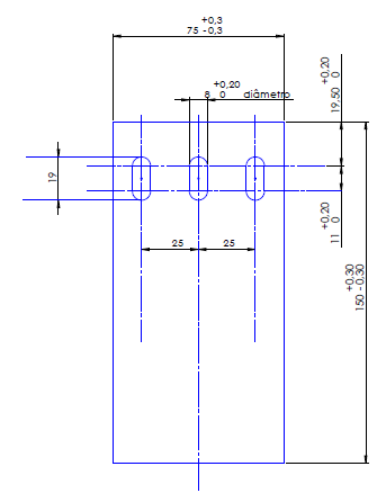

Figura 1: Desenho furo oblongo regular.

Em conformidade com a norma AWS A5.31M os parâmetros de soldagem foram avaliados inúmeras vezes durante a fase de teste, até que os valores ideais fossem alcançados. O objetivo dos testes iniciais é garantir a melhor versão da união pela técnica brasagem MIG [10].

Em todo o processo de união das amostras de PHS e CR4, foi utilizado como material de adição o arame sólido CuSi3, classificados segundo a Norma AWS A5.7 (ERCuSi-A) [11].

E em combinação com o material de adição utilizou-se o gás inerte de proteção argônio (Ar) puro, conforme orientações da norma AWS A5.32 [12].

$O$ ensaio de metalografia, foi realizado para relacionar a estrutura interna do material com suas propriedades físicas.

O ensaio de microdureza Vickers se baseou na resistência que o material oferece à penetração de uma pirâmide de diamante, sob uma determinada carga de 0,5 kgf, e uma distância entre pontos de 0,25 $\mu \mathrm{m}$.

Os ensaios realizados (dureza Vickers e metalografia), se enquadram na norma AWS A5 C3. 3-2008.

\section{Discussão dos resultados}

$\mathrm{Na}$ figura 2 é possível verificar a microestrutura do (a) Aço 22MnB5, (b) PHS e (c) Aço CR4. 


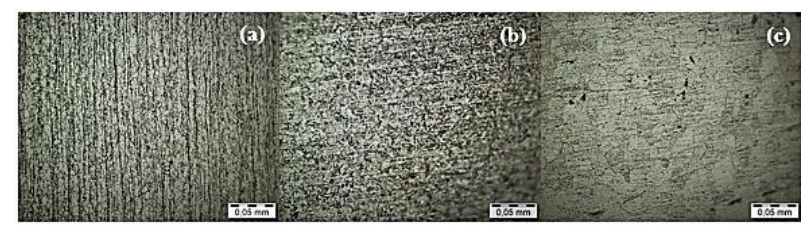

Figura 2: Microestrutura do (a) Aço 22MnB5, (b) PHS e (c) Aço CR4.

Antes do processo de estampagem a quente, o aço 22MnB5 é basicamente formado por áreas claras que representam a ferrita e as áreas escuras, que correspondem a perlita. Desta forma, na figura 2(a) é possível visualizar a micrografia da perlita com lamelas de cementita em uma matriz ferrítica na direção de laminação [4].

Após o processo de estampagem a quente, o aço 22MnB5 é formado por uma matriz martensítica. $\mathrm{Na}$ figura 2(b) é possível visualizar a microestrutura totalmente martensítica, devido ao endurecimento por têmpera [4].

O CR4 é basicamente formado por áreas claras que representam a ferrita e as áreas escuras, que correspondem a perlita. Na figura 2(c) é possível visualizar a microestrutura ferrita/perlita.

Na figura 3, é possível visualizar a diferença entre os resultados de dureza para o aço 22MnB5, o PHS e o CR4.

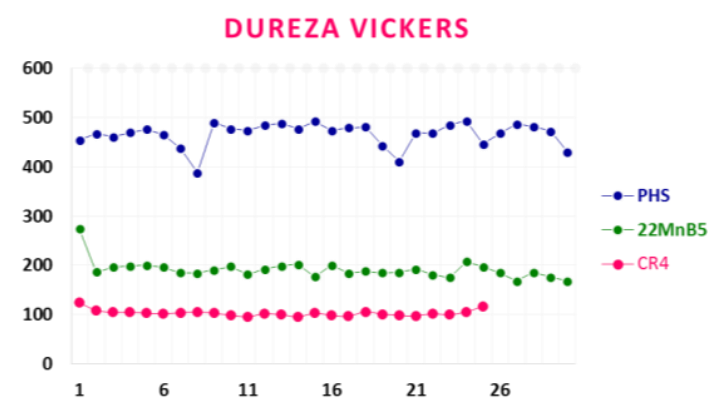

Figura 3: Diferença de dureza entre o aço 22MnB5, do PHS e do CR4.

De acordo com a figura 3 a amostra do aço 22MnB5 antes do processo de estampagem a quente, possuí valores de dureza menores que a amostra de PHS, isso ocorre devido ao tratamento térmico (têmpera) que a amostra de PHS foi submetida.

$\mathrm{Na}$ literatura a dureza do aço 22MnB5 é em torno de $160 \mathrm{HV}$ [13]. É possível associar a figura 2(a) onde a matriz do aço $22 \mathrm{MnB5}$ é ferrita/perlita e nessa microestrutura os valores de dureza ficam em torno de $230 \mathrm{HV}$.

$\mathrm{Na}$ literatura a dureza do PHS é em torno de $430 \mathrm{HV}$ [13]. É possível associar a figura 2(b) onde a microestrutura do PHS é martensítica.

Já a dureza do CR4, na literatura, fica em torno de 230 HV [4]. Na figura 3 nota-se que o aço PHS tem valores de dureza maiores que a amostra de CR4. Este resultado se confirma com as imagens da microestrutura de ambos.
Na tabela 1 é possível verificar o melhor resultado obtido para os parâmetros de soldagem em relação ao processo de união das amostras de PHS e CR4.

Tabela 1: Parâmetros de soldagem.

\begin{tabular}{ll} 
Tabela 1: Parâmetros de soldagem. & \multicolumn{1}{c}{ T1 } \\
\hline \multicolumn{1}{c}{ Parâmetros (unidades) } & \multicolumn{1}{c}{ Th } \\
\hline Velocidade de alimentação do arame $\mathbf{( m / s )}$ & $550^{-3}$ \\
\hline Velocidade de deslocamento $(\mathbf{m} / \mathbf{s})$ & $5,1 \times 10^{-3}$ \\
\hline Corrente de Soldagem $(\mathbf{A})$ & 127,4 \\
\hline Voltagem de soldagem $(\mathbf{V})$ & 10,6 \\
\hline Comprimento do arame (m) & 0,28 \\
\hline Secção Transversal $\left(\mathbf{m}^{\mathbf{2}}\right)$ & $11,116 \times 10^{-6}$ \\
\hline
\end{tabular}

Na figura 4 é possível visualizar o resultado da união das amostras P1.1, P1.2 e P1.3, com os parâmetros T1.

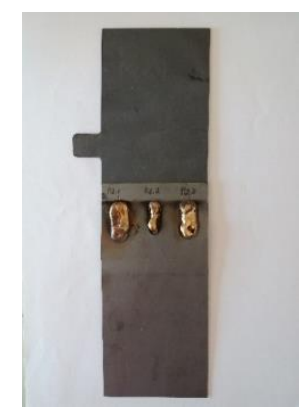

Figura 4: Amostras P1.1, P1.2 e P1.3.

$\mathrm{Na}$ figura 4, em P1.2, não ocorreu um preenchimento completo do furo oblongo regular, já em P1.1 e P1.3, observa-se que houve uma quantidade de material de adição superior a desejada, isso ocorreu devido à alta velocidade de deposição.

$\mathrm{Na}$ figura 5 é possível observar a macrografia das amostras (a) P1.1; (b) P1.2 e (c) P1.3.

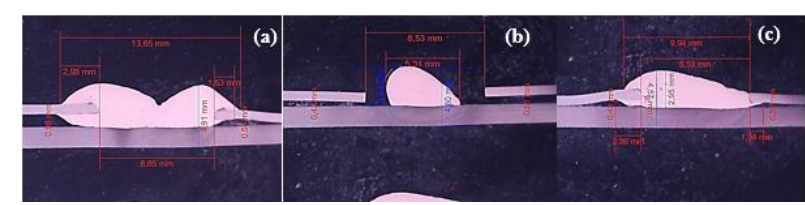

Figura 5: Macrografia das amostras (a) P1.1; (b) P1.2 e (c) P1.3.

Em conformidade com a norma AWS C3. 3-2008, mesmo a amostra P1.1 partindo de espaçamento 0 $\mathrm{mm}$, após o processo, a distância entre o PHS e o CR4 ficou entre $0,4 \mathrm{~mm}$ e $0,6 \mathrm{~mm}$, isso ocorreu devido a penetração por molhabilidade do material de adição.

Já na amostra P1.2, nota-se que o material de adição não preencheu todo o diâmetro do oblongo, isso ocorreu devido a um problema na alimentação do arame.

A amostra P1.3, apresentou visualmente a melhor área brasada, isso ocorreu devido a homogeneidade dos valores obtidos.

A figura 6 ilustra a microestrutura da amostra P1.1, onde é possível visualizar a interface do material de adição com o aço PHS e o CR4. 


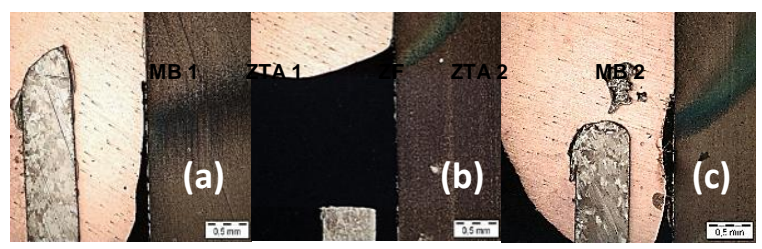

Figura 6: Microestrutura das amostras (a) P1.1, (b) P1.2 e (c) P1.3, com a Interface do material de adição com o PHS e o CR4,

As três amostras (P1.1, P1.2 e P1.3), apresentaram mudanças expressivas na microestrutura do aço PHS. A ZTA do PHS apresentou mudança até mesmo na coloração da imagem. O CR4 não sofreu alteração significativa, e a amostra P1.3, apresenta em meio a zona fundida uma rebarba do material.

Para validar as imagens acima foi realizado o teste de dureza Vickers nas três amostras. $\mathrm{Na}$ figura 7 é possível visualizar os valores de dureza Vickers obtidos para a amostra do P1.1.

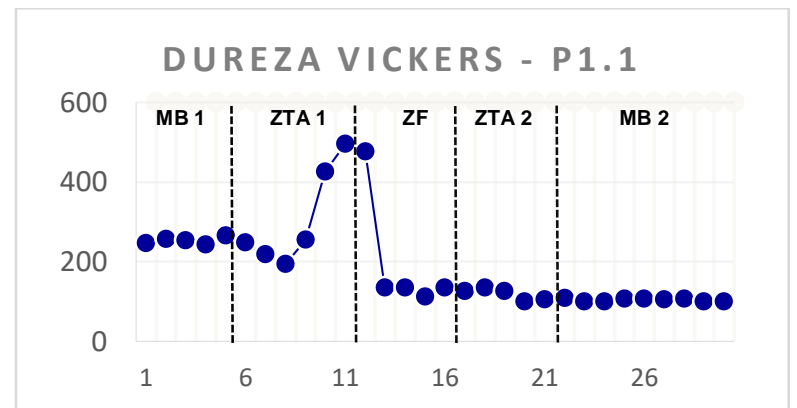

Figura 7: Distribuição de dureza da amostra P1.1.

Na figura 8 é possível observar os valores de dureza Vickers obtidos para a amostra do P1.2.

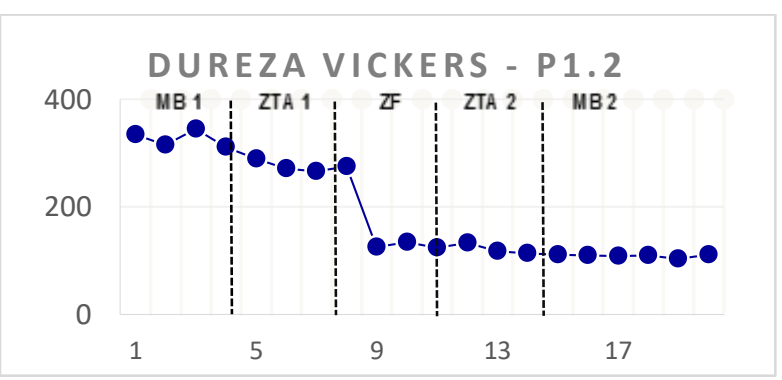

Figura 8: Distribuição de dureza da amostra P1.2.

Já na amostra P1.2, a dureza do PHS está de acordo com a literatura e o CR4 também manteve os valores de dureza equilibrados mesmo na ZTA.

$\mathrm{Na}$ figura 9 é possível visualizar os valores de dureza Vickers obtidos para a amostra do P1.3.

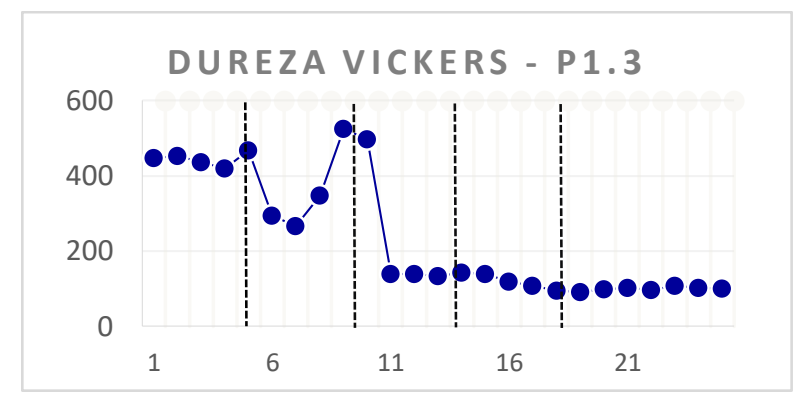

Figura 9: Distribuição de dureza da amostra P1.3.

O ensaio de dureza na amostra P1.3, assim como em P2.1, demonstrou que o CR4 mesmo na ZTA, não demonstrou queda na resistência. Porém, o aço PHS, apresentou uma queda na dureza, tanto na área do material de base, quanto na ZTA, e um aumento significativo até a interface com a ZF.

A queda na resistência no material PHS, nas amostras P1.1 e P1.3, pode ter ocorrido devido a propagação do calor proveniente do processo de união.

De qualquer forma, mesmo com a queda de resistência no PHS, os valores encontrados são aceitáveis, pois quando analisamos a união como um todo, os valores de dureza no PHS, ainda são superiores as do CR4 e do material de adição. Isso demonstra que possivelmente nos testes de tração a fratura ocorrerá no CR4.

\section{Conclusão}

Com base nos experimentos realizados, foi possível concluir que, após o processo de união pelo processo de brasagem MIG, o material de base PHS sofreu mudanças significativas em sua microestrutura, não só com a queda na resistência mecânica na zona termicamente afetada pelo calor (ZTA), mas também em toda a área da secção transversal. Isso ocorre devido a propagação do calor do processo de união, onde o resfriamento é lento e a mudança na microestrutura afeta a resistência final do material. Já o aço CR4, não demonstra significativa alteração microestrutural e mantém suas propriedades físicas.

\section{Agradecimentos}

Os autores agradecem a CAPES pelo apoio financeiro, a empresa Brunning pelo fornecimento do aço, a empresa Lincoln Electric por permitir o processo de união e o Centro Universitário Fundação Santo André pela parceria nos ensaios.

\section{Referências}

[1] ROTA 2030. "O que é o Rota 2030? ”. Disponível em: <https://www.rota2030.com.br/rota-2030inovacao/> Acesso em: 26/02/2020.

[2] SENADO. Projeto de Lei do Senado $n^{\circ} 152$ de 2017. "Altera a Lei $n^{\circ}$ 9.503, de 23 de setembro de 1997, que institui o Código de Trânsito Brasileiro, para determinar que somente poderão ser comercializados os modelos de 
veículos que tenham alcançado resultados mínimos em testes de impacto (crash tests)".

[3] OLIVEIRA, L.; MENDES. P. "Comissão aprova obrigatoriedade de proteção lateral em carros". Disponível em: < http://g1.globo.com/carros/noticia/2014/11/comis sao-aprova-obrigatoriedade-de-protecao-lateralem-veiculos.html > Acesso em: 10/06/2020.

[4] ALTAN, T. "Hot Stamping Boron-Alloyed Steels for Automotive Parts - Part I: Process Methods and Uses". Stamping Journal, 2006, p. 40-41.

[5] KARBASIAN, H.; TEKKAYA, A.E. "A Review on hot stamping". Journal of Materials Technology, Elsevier, Dortmund, 2010.

[6] $\mathrm{CHOI}, \mathrm{H}$. S. et al. "Evaluation of weldability for resistance spot welded single lap joint between GA780DP and hot-stamped 22MnB5 steel sheets". Journal of Mechanical Science and Technology, 2011.

[7] DURFFY, J.E.; SCHARFF, R. "Auto Body Repair". 4 ed. New York: Thomson Delmar Learning, 2004.

[8] HARRIS. "Boletim técnico processo MIG Brazing". Sulzer Metco. Santo André - Brasil, 2015.

[9] AWS (American Welding Society, Inc.) C3. 3-2008 "Recommended Practices for the Design, Manufacture, and Examination of Critical Brazed Components". Edição 2008.

[10] AWS (American Welding Society, Inc.) A5.31M/A5.31:2012 "Specification for Fluxes for Brazing and Braze Welding”. Edição 2012.

[11] AWS (American Welding Society, Inc.) A5.7 "Especification for Cupper and Cupper Alloy Bare Welding Hot and Electrods". Edição 2007, 2007.

[12] AWS (American Welding Society, Inc.) A5. 32 "Welding Consumables-Gases and Gas Mixtures for Fusion Welding and Allied Processes". Edição 2011.

[13] GORNI, A. A. "Novas tendências para o processo de estampagem a quente". Editora: Corte \& Conformação de Metais, 2010. 